\title{
Beta-Radiation for Coronary In-Stent Restenosis
}

\author{
Donald R. Latchem, мввs, Philip Urban, ${ }^{* \dagger}$ MD, Jean-Jacques Goy, MD, \\ Edoardo De Benedetti, MD, Alessia Pica, MD, Philippe Coucke, MD, and Eric Eeckhout, MD, PhD
}

\begin{abstract}
To determine the feasibility and safety of an intracoronary beta-radiation device in preventing the recurrence of in-stent restenosis (ISR) after successful angioplasty, we studied 37 patients treated with beta-radiation $(30-\mathrm{mm}$ strontium- 90 source) after angioplasty. The mean reference diameter was $2.9 \pm 0.5 \mathrm{~mm}$, and $62 \%$ of lesions were diffuse, including four total occlusions. Beta-radiation was successfully delivered in 36 of 37 $(97 \%)$ cases. Over the course of $7.1 \pm 4.5$ mo follow-up, there were no myocardial infarctions and three deaths: one from preexisting malignancy, one from progressive cardiac failure, and one from sudden cardiac death. Target vessel revascularization (TVR) was performed in seven of $36(19 \%)$ patients. Thirty patients underwent angiography at 6 mo; three $(10 \%)$ experienced restenosis (diameter stenosis $>50 \%$ ) at the target site, four $(13 \%)$ had edge stenoses, and two $(7 \%)$ had late $(>1 \mathrm{mo})$ thrombotic occlusions. Beta-radiation for ISR is associated with encouragingly low rates of target lesion restenosis and TVR. Further improvements are needed to solve the limitations of the edge effect and late occlusion. Cathet. Cardiovasc. Intervent. 51:422-429, 2000.

(1) 2000 Wiley-Liss, Inc.
\end{abstract}

Key words: angioplasty; radiation; in-stent restenosis

\section{INTRODUCTION}

Restenosis after percutaneous coronary intervention limits the long-term therapeutic benefit of this procedure and results in significant morbidity and additional costs. Restenosis occurs in 30-60\% [1,2] of cases after balloon angioplasty and is symptomatic in the majority of patients, necessitating a second attempt at revascularization. It is thought to result from two concurrent mechanisms of action in response to mechanical injury to the vessel wall: intimal hyperplasia and negative arterial remodeling (vessel shrinkage), a result of early elastic recoil and, later, adventitial fibrosis. In two landmark studies, the coronary stent has been shown to reduce significantly the incidence of restenosis compared with balloon angioplasty alone [3,4]. This fact, together with improved immediate angiographic outcome and reduced acute closure, has led to a dramatic increase in their use worldwide since the early 1990s; the majority of centers now deploy stents in $70-80 \%$ of cases. Intravascular ultrasonographic studies have taught us that stents primarily prevent restenosis by eliminating negative remodeling [5]. Stents, however, do not limit intimal hyperplasia. In fact, the opposite is true [5]. Excessive intimal hyperplasia is thought to account for the phenomenon of in-stent restenosis that occurs in $10-35 \%$ of cases. Several different percutaneous approaches can be attempted to treat this condition: balloon angioplasty [6,7], stenting [8-10], rotational atherectomy [11], excimer laser angioplasty [12,13], and cutting balloon [14]. While immedi- ate angiographic and clinical outcomes are usually good, the reported recurrent restenosis rates at 6 mo range widely $(22-85 \%)$. Target vessel revascularization rates at $1 \mathrm{yr}$ are $11-19 \%$ for focal lesions ( $\leq 10 \mathrm{~mm}$ ), $35 \%$ for diffuse lesions ( $>10 \mathrm{~mm}$ ), $50 \%$ for proliferative lesions (>10 $\mathrm{mm}$ and extending beyond the stent borders), 83\% for total occlusions, and $100 \%$ for saphenous vein grafts [6-20].

Intracoronary radiotherapy is a new method that has been shown to reduce significantly neointimal formation in animal models of restenosis [21]. Several clinical trials in humans have confirmed the efficacy and safety of gamma- and beta-radiation in limiting restenosis at the target site after balloon angioplasty in both de novo and restenotic lesions, compared with controls [22-25]. We report our experience with 37 patients using in-stent

Divisions of Cardiology and Radiation Oncology, Centre Hospitalier Universitaire Vaudois, Lausanne, Switzerland

\footnotetext{
${ }^{\dagger}$ In accordance with the policy of the Journal, the designated author discloses a financial or other interest in the subject discussed in this article.
}

Grant sponsor: Amy and Athelstan Saw Overseas Medical Scholarship.

*Correspondence to: Dr. P. Urban, Cardiovascular Department, La Tour Hospital, 1217 Geneva, Switzerland. E-mail: philip.urban@latour.ch

Received 6 March 2000; Revision accepted 11 July 2000 
restenosis with a novel catheter-based beta-emitting device (Beta-Cath; Novoste Europe SA/NV, Brussels, Belgium).

\section{METHODS}

\section{Study Design and Patient Population}

Between October 1998 and December 1999, we enrolled 37 consecutive patients with in-stent restenosis and evidence of ischemia. The study protocol was approved by the ethics committee at our institution, and written informed consent was obtained from each patient.

\section{Procedure}

All patients received intra-arterial or intravenous heparin sufficient to maintain an activated clotting time of between 300 and $350 \mathrm{sec}$. Large lumen (0.86 inch) $8 \mathrm{~F}$ guiding catheters (Vector; Medtronic Intervention Vascular Inc., Danvers, MA) were used. The lesions were dilated with standard $20-\mathrm{mm}$ balloon catheters in the usual way. Additional stenting was not undertaken unless indicated for significant dissection, proximal or distal to the target lesion. When necessary, the stents were always deployed after intracoronary radiotherapy. The use of the glycoprotein IIb/IIIa inhibitor abciximab was left to the discretion of the operator. Following the procedure, all patients were continued on aspirin at $100 \mathrm{mg} /$ day. Ticlopidine or clopidogrel was given for the first month if additional stenting was required; as of March 1999, it was decided to give all patients $300 \mathrm{mg}$ of clopidogrel on the day of the procedure, followed by $75 \mathrm{mg} /$ day for 3-6 mo.

\section{The Beta-Radiation Device}

The Beta-Cath device consists of a hand-held, multiple-use transfer device, a $5 \mathrm{~F}$ delivery catheter, and a 30 -mm source train of strontium-90 seeds (a pure betaemitter) sealed in 12 independent cylinders. The safety and feasibility of this device has been evaluated for de novo lesions [22]. Following balloon angioplasty, the delivery catheter is advanced over the standard 0.014inch guide wire, using the monorail channel, and placed precisely across the lesion and barotraumatized segment using proximal and distal radiopaque markers. The attending radiation oncologist hydraulically delivers the source train by a sterile water-filled syringe from the transfer device to the target site through the closed-end delivery catheter in a few seconds. The source is maintained at the target site by continuously applying gentle pressure on the flushing syringe. The device is in a closed-loop system; no fluid is injected into the coronary artery, and the source train is never in contact with the patient's blood. The prescribed dose is $16 \mathrm{~Gy}$ at $2 \mathrm{~mm}$ from the source for vessels of $2.7-3.3 \mathrm{~mm}$ in diameter or $20 \mathrm{~Gy}$ at $2 \mathrm{~mm}$ for vessels $3.4-4.0 \mathrm{~mm}$. Upon completion of the procedure and retrieval of the source train into the transfer device, only the delivery catheter needs to be discarded. The source train is kept inside the transfer device and placed in a radiation storage site until the next procedure. During the entire procedure, two cardiologists, a radiation oncologist, and a physicist (to measure the radiation activity) are present. No additional shielding is required.

\section{Angiography and Quantitative Coronary Angiographic Analysis}

Angiography was carried out in the same orthogonal views before and after percutaneous transluminal coronary angioplasty (PTCA) and radiotherapy and at follow-up for each patient. In addition, efforts were made to document each position of the angioplasty balloon and source train on film (Fig. 1a-c). Following administration of intracoronary isosorbide dinitrate, a diastolic frame with sharply defined edges without foreshortening and overlap was selected for quantitative coronary analysis. The $8 \mathrm{~F}$ guiding catheter was used as the calibration standard. The percent diameter stenosis, the diameter of the reference vessel, and the minimal luminal diameter of the lesion segment were determined in the usual manner using an edge-detection program (Advantage; General Electric Medical Systems, Milwaukee, WI). In addition, to analyze the effects of radiation at the edges of the target lesion, we took these same measurements on selected segments at varying distances both proximal and distal to the lesion, using readily identifiable landmarks (e.g., angulations, branch points, other stents). The segment of artery that was ballooned and/or irradiated was considered the treated segment. Acute gain (in millimeters) was defined as the change in the target site's minimal luminal diameter (MLD) from baseline to the result immediately after the procedure. Late loss (in millimeters) was defined as the change in target site MLD from immediately post-procedure to follow-up angiography. The late loss index was defined as the ratio of late loss to acute gain. Each angiogram was reviewed for the presence or absence of "geographic miss," defined as a margin of radiation source/balloon overlap of $<5 \mathrm{~mm}$ at both ends [26].

\section{Follow-Up and End Points}

Clinical follow-up was undertaken at 30 days and at 6-8 mo by telephone contact with the patient and/or the treating physician. The following clinical end points were evaluated during the study period: procedural success and major adverse cardiac events (myocardial infarction, urgent or elective target vessel revascularization, and death). Procedural success was defined as the 
TABLE I. Baseline Clinical and Angiographic Characteristics*

\begin{tabular}{lc}
\hline Total no. & 37 \\
Age (yr) & $61 \pm 11$ \\
Male sex, no. (\%) & $28(76 \%)$ \\
Diabetes, no. (\%) & $8(22 \%)$ \\
Angina NYHA grade, no. (\%) & \\
I & 0 \\
II & $14(38 \%)$ \\
III & $7(19 \%)$ \\
IV & $13(35 \%)$ \\
Postinfarction, no. (\%) & $3(8 \%)$ \\
Target lesion site & \\
Left anterior descending artery & $11(30 \%)$ \\
Left circumflex artery & $6(16 \%)$ \\
Marginal & $1(3 \%)$ \\
Right coronary artery & $16(43 \%)$ \\
Saphenous vein graft & $3(8 \%)$ \\
Lesion length (mm) & $14.6 \pm 10.4$ \\
Diffuse lesions, no. (\%) & $23(62 \%)$ \\
\hline
\end{tabular}

*NYHA, New York Heart Association.

successful delivery of the prescribed dose and residual stenosis not greater than $30 \%$ (by visual estimation) of the luminal diameter after PTCA without myocardial infarction, death, or urgent target vessel revascularization within 30 days of the index procedure. Myocardial infarction was defined as an elevation of the creatine kinase and creatine kinase-MB levels more than twice the upper limit of normal or by the appearance of pathological Q waves on the electrocardiogram. Revascularization was carried out at the discretion of the treating cardiologist. Follow-up angiography was done at 6-8 mo after the index procedure, unless the clinical situation warranted earlier evaluation. The angiographic end point was restenosis, defined as a percentage diameter stenosis of $\geq$ $50 \%$. All data were entered into a computerized database and expressed as proportions or as means plus or minus the standard deviation.

\section{RESULTS \\ Study Population and Procedural Outcome}

Thirty-seven consecutive patients were enrolled. The baseline clinical and angiographic characteristics are shown in Table I. The patients' ages averaged $61 \pm 11 \mathrm{yr} ; 76 \%$ were male, $22 \%$ had diabetes, $46 \%$ had disease affecting more than one vessel, and 54\% had New York Heart Association class III or IV angina. Thirty-four lesions were in native coronaries, and the remaining three lesions were in saphenous vein grafts. Eight patients (22\%) had had more than one recurrence at the same site. The mean reference diameter was $2.9 \pm 0.5 \mathrm{~mm}$, with a mean diameter stenosis of $71.2 \pm 17.3 \%$. Fifteen lesions $(40 \%)$ were focal (length $\leq 10 \mathrm{~mm}), 14(38 \%)$ were diffuse (length $>10 \mathrm{~mm}$ within the stent), and four (11\%) were proliferative $(>10$ mm extending outside the stent). There were four (11\%) totally occluded stents, giving a mean lesion length of $14.6 \pm 10.4 \mathrm{~mm}$. Balloon angioplasty was successful in all cases. In four cases (11\%) additional stent implantation was necessary to treat dissection beyond the target site, and one of these patients also received abciximab. No patients received a stent within the stent. In one case (3\%), placement of the delivery catheter was unsuccessful after PTCA, because of proximal vessel tortuosity. This patient, who had no complications, was excluded from clinical and angiographic follow-up. The mean prescribed dose was $18.0 \pm$ $2.2 \mathrm{~Gy}$ at a distance of $2 \mathrm{~mm}$ from the source, with a mean dwell time of $3.7 \pm 0.4 \mathrm{~min}$. In six cases (16\%) the operator attempted to irradiate the full length of the lesion by first placing the source train across the distal segment and then repositioning the delivery catheter and source across the proximal segment. This "pullback" maneuver resulted in a short, middle segment of the lesion effectively receiving twice the dose. Geographic miss during the index procedure occurred in 17 cases (46\%) and was unavoidable in most cases (e.g., the lesion length exceeded the source length, or additional stents were needed for dissection beyond the target site). The four patients (11\%) who underwent stenting were given short courses of antiplatelet therapy ( $\leq 1 \mathrm{mo})$, but as of March 1999 all the subsequent 17 (46\%) patients received prolonged (3-6 mo) antiplatelet therapy. At 30 days there were no cases of subacute stent thrombosis, target vessel revascularization, myocardial infarction, or death. The procedural success rate was therefore 36 of 37 (97\%).

\section{Clinical Follow-up}

At a mean clinical follow-up time of $7.1 \pm 4.5 \mathrm{mo}$, there were no myocardial infarctions, and three patients had died. One patient, who experienced a severe lesion on the proximal left anterior descending artery at the edge of the target site, died suddenly while awaiting coronary bypass surgery. Another died from known, disseminated prostatic carcinoma 6 mo after the procedure. The third patient died from progressive cardiac failure at $21 / 2$ mo, without signs of recurrent ischaemia. This last patient, who was not a surgical candidate, had severe three-vessel disease, three occluded bypass grafts, and an ejection fraction of 0.28 . The target lesion was the right coronary artery, which was supplying collaterals to the left coronary system and had been redilated seven times. One patient had acute onset of new exertional angina, as the result of late $(>1 \mathrm{mo})$ stent thrombotic occlusion approximately $31 / 2$ mo after the procedure. Target vessel revascularization was necessary in seven of 36 (19.4\%) patients; a second PTCA was performed in four and coronary artery bypass grafting in three. 

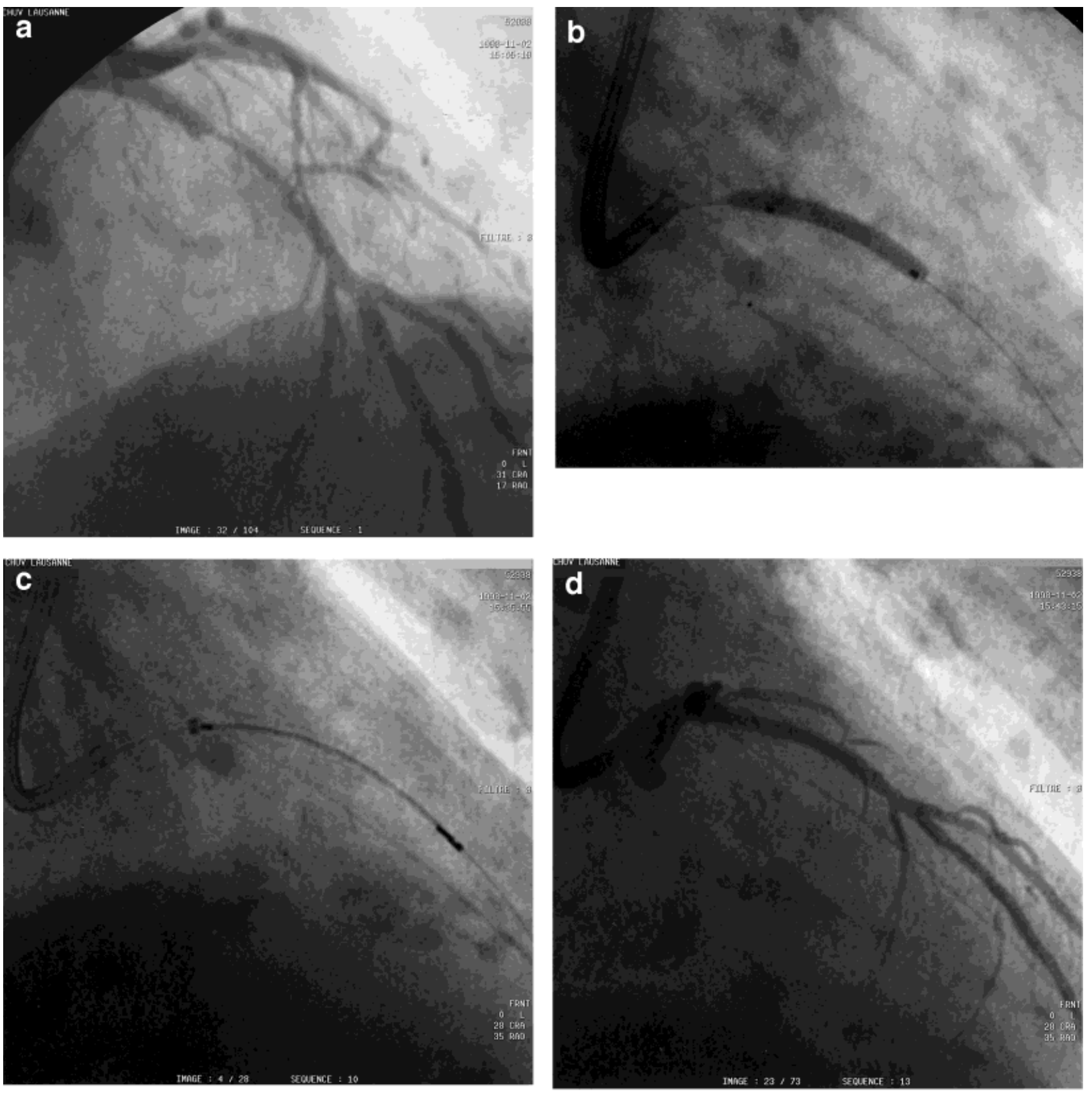

Fig. 1. a: Coronary angiogram of a significant in-stent restenosis in the left anterior descending coronary artery. b: Angioplasty with a $20-\mathrm{mm}$ balloon. c: Position of the $30-\mathrm{mm}$ source train (between the radiopaque markers) within the delivery

\section{Angiographic Follow-up and Quantitative Coronary Analysis}

Angiographic follow-up information was obtained for 30 of $36(83 \%)$ patients at a mean time of $5.3 \pm 1.9$ mo (Table II). Two deaths occurred before angiographic follow-up, two patients refused angiographic follow-up

catheter, with adequate overlap at either end of the stent. d: The final result after angioplasty and irradiation. e: (see next page) No significant restenosis at 6-mo follow-up.

(both were asymptomatic with negative results of functional tests at $6 \mathrm{mo}$ ), and another two asymptomatic patients were still to undergo angiography at the time of writing. Target-site restenosis was found in three of 30 $(10 \%)$, and all three showed signs of recurrent angina. These three patients had had focal stenoses in native 


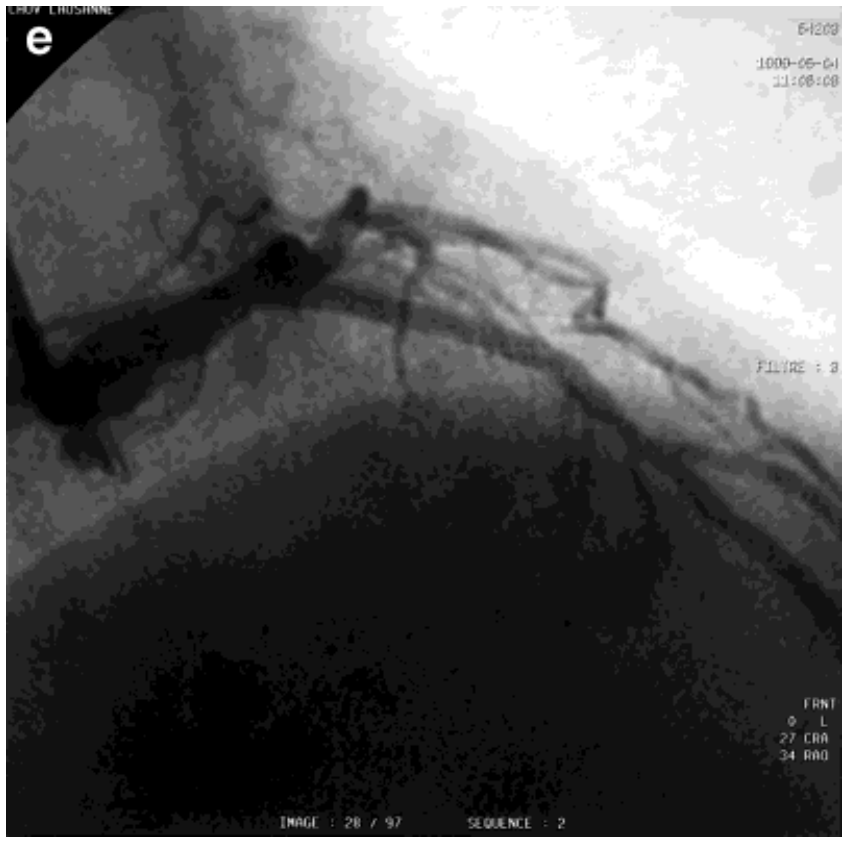

Figure 1. (Continued.)

coronaries. Four $(13 \%)$ other patients had new lesions beyond the target site (but within the treated segment), and two of them were symptomatic. Geographic miss during the index procedure had occurred in three of these patients. Two patients $(7 \%)$ were found to have late thrombotic occlusions (at 3.5 and 6, mo, respectively); neither had had total occlusions originally.

On quantitative coronary analysis (Table 2), performed on all nonoccluded treated segments, the MLD went from $0.7 \pm 0.4 \mathrm{~mm}$ to $2.1 \pm 0.3 \mathrm{~mm}$ immediately after treatment and then to $2.0 \pm 0.6 \mathrm{~mm}$ at follow-up, with a late loss index of only $0.15 \pm 0.28 \mathrm{~mm}$. The MLD of the proximal and distal segments went from $2.6 \pm 0.7$ $\mathrm{mm}$ and $2.0 \pm 0.5 \mathrm{~mm}$ to $2.6 \pm 0.7 \mathrm{~mm}$ and $2.1 \pm 0.4$ $\mathrm{mm}$, respectively, immediately after treatment and then to $2.5 \pm 0.8 \mathrm{~mm}$ and $2.1 \pm 0.4 \mathrm{~mm}$, respectively, at follow-up. The cumulative distribution curves of the MLD before and after angioplasty and at follow-up are shown in Fig. 2, and it can be seen that late loss is small in the majority of patients. In three patients, the MLD was larger at follow-up compared with the result immediately after angioplasty. Positive remodeling has been described after radiation therapy of nonstented segments [22]. In two of the three cases this could be explained by inclusion of the stent borders in the lesion QCA analysis (because the lesions extended beyond the stent). In one patient, in whom the pullback maneuver had been performed, marked positive remodeling (maximum diameter of $5.1 \mathrm{~mm}$ on QCA) was observed in the segment that had received the cumulative dose.
TABLE II. Immediate Outcomes and Follow-up

\begin{tabular}{lc}
\hline Procedural success & $36 / 37(97 \%)$ \\
Death & $3 / 36(8.3 \%)$ \\
$\quad$ Sudden cardiac death & 1 \\
Cardiac failure & 1 \\
Malignancy & 1 \\
Myocardial infarction & $0 / 36(0 \%)$ \\
Target vessel revascularization & $7 / 36(19.4 \%)$ \\
Coronary bypass grafting & $3 / 36(8.3 \%)$ \\
Balloon angioplasty & $4 / 36(11.1 \%)$ \\
6-mo angiographic follow-up & $30 / 36(83 \%)$ \\
Target lesion restenosis & $3 / 30(10 \%)$ \\
Edge recurrence & $4 / 30(13.3 \%)$ \\
Late stent occlusion & $2 / 30(6.7 \%)$ \\
\hline
\end{tabular}

\section{DISCUSSION}

This study demonstrates the feasibility and safety of a passively centered, catheter-based beta-radiation device in preventing restenosis after balloon angioplasty in patients with in-stent restenosis. Our results are consistent with those of other studies that document a lower than expected recurrence rate in patients with in-stent restenosis treated by intracoronary gamma- and, more recently, beta-radiation. In a randomized placebo-controlled trial of a catheter-based gamma-emitter (iridium192), Teirstein et al. [23] found a 6-mo angiographic restenosis rate of $17 \%$ in patients with restenotic lesions (62\% with in-stent restenosis) compared with $54 \%$ in the placebo group. In a similar study, the WRIST (Washington Radiation for In-stent Restenosis Trial) by Waksman et al [24], also using a noncentered iridium-192 source, a binary angiographic restenosis rate of $19 \%$ was reported, versus $58 \%(P=0.001)$ in the placebo arm. This lower restenosis rate in the treatment group was associated with significantly fewer target lesion revascularization procedures (13.8\% vs. $63.1 \%)$ and fewer major adverse cardiac events (29.2\% vs. $67.7 \%)$ at 6 mo, compared with controls.

Equally impressive reductions in these end points have been reported with beta-radiation. Popma presented the results of the Stents and Radiation Therapy (START) trial [27], which utilized the same beta-radiation device as in our study and documented a $66 \%$ reduction in binary angiographic restenosis $(14.2 \%$ vs. $41.2 \%$; $P<$ 0.001 ) and $34 \%$ reduction in the need for target vessel revascularization $(16 \%$ vs. $24 \% ; P=0.026)$ compared with the placebo group. By way of contrast, Sabaté et al. [28], using the same beta-radiation device, had a recurrence rate of $53 \%$, leading to a target vessel revascularization rate of $47 \%$ in 18 patients with a history of at least two recurrences of in-stent restenosis. They documented geographic miss in $44 \%$ of all cases. Seventy-eight percent of the recurrences were at the edge of the irradiated area, and the vast majority (86\%) of these edge recur- 
TABLE III. Angiographic Results at 6 mo*

\begin{tabular}{lccc}
\hline & Pre-procedure $^{\mathrm{a}}$ & Post-procedure $^{\mathrm{a}}$ & Follow-up $^{\mathrm{a}, \mathrm{b}}$ \\
\hline Reference vessel (mm) & $2.9 \pm 0.5$ & $2.8 \pm 0.4$ & $2.9 \pm 0.4$ \\
Lesion MLD (mm) & $0.7 \pm 0.4$ & $2.1 \pm 0.3$ & $2.0 \pm 0.6$ \\
Diameter stenosis (\%) & $71.2 \pm 12.3$ & $24.8 \pm 10.6$ & $30.2 \pm 19.3$ \\
Proximal segment MLD (mm) & $2.6 \pm 0.7$ & $2.6 \pm 0.7$ & $2.5 \pm 0.8$ \\
Distal segment MLD (mm) & $2.0 \pm 0.5$ & $2.1 \pm 0.4$ & $2.1 \pm 0.4$ \\
Change in minimal luminal diameter & & & \\
$\quad$ Acute luminal gain & & $1.4 \pm 0.4 \mathrm{~mm}$ & \\
$\quad$ Late luminal loss & & $0.2 \pm 0.4 \mathrm{~mm}$ & \\
$\quad$ Late loss index & & $0.15 \pm 0.28$ & \\
\hline
\end{tabular}

*MLD, minimal luminal diameter.

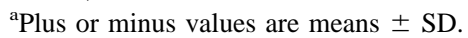

${ }^{b}$ Excludes occluded stents.

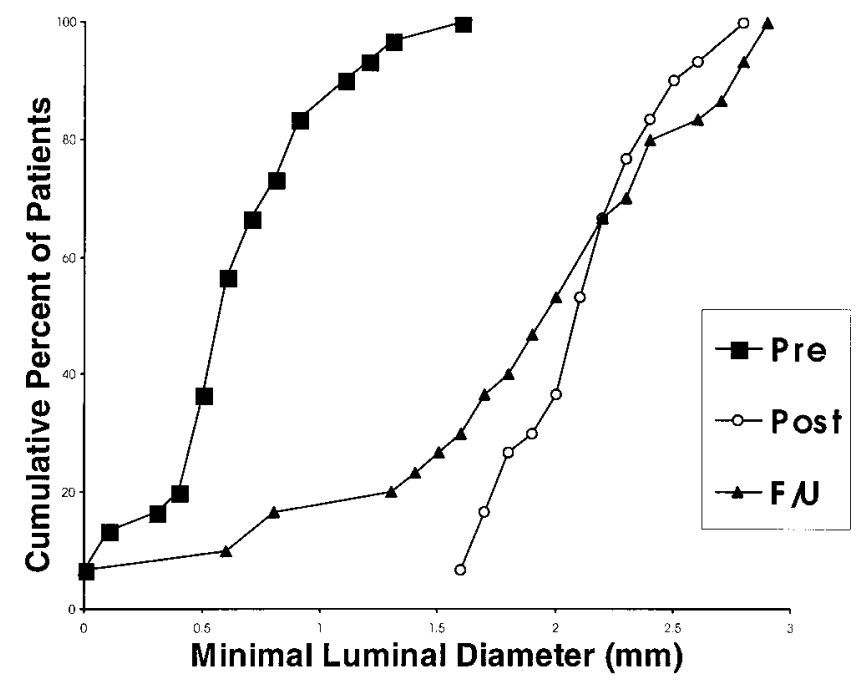

Fig. 2. Minimal luminal diameter cumulative distribution curves. Pre, before angioplasty; Post, immediately after angioplasty, F/U, follow-up angiography.

rences were in areas of documented geographic miss. This "edge effect" is thought to be a consequence of geographic miss, where a segment of artery is barotraumatized by the balloon but receives inadequate radiation because it lies in the radiation dose "falloff" zone, allowing the formation of intimal hyperplasia and negative arterial remodeling [26]. It can be seen from our study that the edge effect accounted for the majority of recurrences, including the patient who died suddenly. The edge effect has been described in the other clinical trials of both beta and gamma-emitting catheter-based devices [24,25,27] and beta-emitting stents [29]. In START [27], an additional $14.6 \%$ recurrences were at the edges in the radiation arm, compared with only $4 \%$ of the placebo group. In WRIST [24], 6-mo target lesion revascularization was reported as $13.8 \%$ in the irradiated group but target vessel revascularization was necessary in another $12.1 \%$, whereas in the placebo group the two forms of treatment differed by only $4.7 \%$, suggesting an excess of the edge effect in the treatment group.

Similarly, in the GAMMA 1 [25] trial, one-third of the recurrences $(10.8 \%)$ were at the stent edge in the irradiated group, as opposed to only $6.8 \%$ of all recurrences in the placebo group. The edge effect is even more apparent with radioactive stents. In a dose-finding study, with Palmaz-Schatz 153 and BX Isostent stents, restenosis at the proximal and distal ends of the stent occurred in $43-62 \%$ of cases. In-stent intimal hyperplasia was markedly reduced, giving the typical "candy wrapper" appearance [29], presumably because the shoulder of the stentdeploying balloon lies in the dose falloff zone. From our study, we estimate that geographic miss results in a risk of approximately $18 \%$ for the edge effect. This highlights the importance of covering the entire balloon-injured segment, with considerable overlap, when using intracoronary radiation. Heightened awareness of this problem and the availability of longer source trains in the near future should translate into improved results.

Another important issue is that of late stent thrombosis. One of our patients, who did not have a new stent implanted, showed signs of this complication 5 days after completing a 3-mo course of ticlopidine. The second, who had had a 1-mo course of ticlopidine, did not experience angina and was found to have an occluded stent only at angiographic follow-up. This phenomenon has been observed in most intracoronary radiation studies, with incidence rates between $5 \%$ and $15 \%$ (with the highest incidence rates seen after stenting) [30,31]. In the absence of radiotherapy, by way of comparison, total occlusions have been documented in $4.1 \%$ of patients at angiographic follow-up. In these cases, in-stent restenosis is treated with balloon angioplasty and provisional stenting [9]. It is now clear that arterial trauma invariably follows balloon angioplasty and that radiotherapy delays the natural healing process, including endothelialization of the stent, leaving the artery and stent vulnerable to thrombosis for a prolonged period of time $[32,33]$. It is 
encouraging that the use of prolonged combined antiplatelet therapy in the START trial [27] resulted in no late clinical thrombotic events and that the frequency of total occlusions at 8-mo angiographic follow-up was similar in the placebo (3.7\%) and irradiated groups $(4.0 \%)$. This finding is consistent with those of the nonradiation study cited earlier.

As noted earlier, total occlusions, diffuse lesions, and location in a saphenous vein graft carry a high risk of recurrence after a second PTCA for in-stent restenosis, as do such clinical factors as diabetes [20,34]. While we do not have a control group for comparison, our observed target site restenosis rate of $10 \%$ and target vessel revascularization rate of $19.4 \%$ is encouraging, given that 27 of $36(75 \%)$ of our patients had at least one of these risk factors. This study confirms the START study findings that the user-friendlier beta-radiation appears to be as effective in the treatment of in-stent restenosis as gamma-radiation. Despite theoretical concerns regarding the steeper dose falloff profile with beta-radiation, there does not seem to be an excess of edge recurrences compared with the gamma trials, and, unlike gamma sources, there is the advantage of lower-risk exposure to the patient and laboratory personnel $[21,35]$. Overall, the study shows that beta-radiation therapy can be integrated easily into the conventional catheter laboratory setting, with easy-to-follow dosimetry protocols without the need for intravascular ultrasonography.

\section{Limitations of the Study}

This is a relatively small study, without a control group for direct comparison. Nevertheless, we believe that our findings compare favorably with previously documented results on repeated interventions for in-stent restenosis and are consistent with those of other published series on intracoronary radiation therapy.

\section{CONCLUSIONS}

Intracoronary beta-irradiation is a breakthrough treatment for in-stent restenosis after balloon angioplasty, with encouragingly low rates of target lesion restenosis and need for target vessel revascularization. This benefit, however, is diminished by problems with the edge effect and late stent occlusion. The solution to these problems will lie, most probably, in minimizing the geographic miss rate by careful attention to balloon and source train placement, the availability of longer source trains, and continuing combined antiplatelet therapy for longer periods of time.

\section{ACKNOWLEDGMENTS}

Dr. D.R. Latchem is supported by the Amy and Athelstan Saw Overseas Medical Scholarship from the Uni- versity of Western Australia, Nedlands WA 6009, Australia. The authors acknowledge the assistance of the cardiac catheterization staff, the radiation physicists, Mr. S. Raimondi and Mr. H. P. Do, and our research nurse Ms. Maaike Staverman.

\section{REFERENCES}

1. Gruentzig AR, King SB III, Schlumpf M, Siegenthaler W. Longterm follow-up after percutaneous transluminal coronary angioplasty: the early Zurich experience. N Engl J Med 1987;316: $1127-1132$.

2. Holmes DR, Vliestra RE, Smith HC. Restenosis after percutaneous transluminal coronary angioplasty (PTCA): a report from the PTCA registry of the National Heart, Lung and Blood Institute. Am J Cardiol 1984;53:77C-81C.

3. Fischman DL, Leon MB, Baim DS, Schatz RA, Savage MP, Penn I, Detre K, Veltri L, Ricci D, Nobuyoshi M, Cleman M, Heuser R, Almond D, Teirstein PS, Fish RD, Colombo A, Brinker J, Moses J, Shaknovich A, Hirshfeld J, Bailey S, Ellis S, Rake R, Goldberg S. A randomized comparison of coronary-stent placement and balloon angioplasty in the treatment of coronary artery disease. N Engl J Med 1994;331:496-501.

4. Serruys PW, DeJaegere P, Kiemeneij F, Macaya C, Rutsch W, Heyndrickx G, Emanuelsson H, Marco J, Legrand V, Materne P, Belardi J, Sigwart U, Colombo A, Goy JJ, Van Den Heuvel P, Delcan J, Morel M. A comparison of balloon-expandable-stent implantation with balloon angioplasty in patients with coronary artery disease. N Engl J Med 1994;331:489-495.

5. Hoffmann R, Mintz GS, Dussaillant GR, Popma JJ, Pichard AD, Satler LF, Kent KM, Griffin J, Leon MB. Patterns and mechanisms of in-stent restenosis a serial intravascular ultrasound study. Circulation 1996;94:1247-1254.

6. Bauters C, Banos J-L, Van Belle E, Mc Fadden EP, Lablanche J-M, Bertrand ME. Six-month angiographic outcome after successful repeat percutaneous intervention for in-stent restenosis. Circulation 1998;97:318-321.

7. Reimers B, Moussa I, Akiyama T, Tucci G, Ferraro M, Martini G, Blengino S, Di Mario C, Colombo A. Long-term clinical follow-up after successful repeat percutaneous intervention for stent restenosis. J Am Coll Cardiol 1997;30:186-192.

8. Satler LF. Remedies for in-stent restenosis. Cathet Cardiovasc Diagn 1996;37:320-321.

9. Elezi S, Kastrati A, Hadamitzky M, Dirschinger J, Neumann FJ, Schomig A. Clinical and angiographic follow-up after balloon angioplasty with provisional stenting for coronary in-stent restenosis. Cathet Cardiovasc Intervent 1999;48:151-156.

10. Al-Serangi HS, Ho PC, Nesto RW, Lewis SM, Leeman D, Fitzpatrick P, Mittleman M, Waxman S, Shubrooks SJ. Stenting for in-stent restenosis: a long-term clinical follow-up. Cathet Cardiovasc Intervent 1999;48:143-148.

11. Stone GW. Rotational atherectomy for treatment of in-stent restenosis: role of intracoronary ultrasound guidance. Cathet Cardiovasc Diagn 1996;37(Suppl 3):73-77.

12. Köster R, Hamm C, Terres W. Treatment of in-stent coronary restenosis by excimer laser angioplasty. Am J Cardiol 1997;80: $1424-1428$.

13. Mehran R, Mintz GS, Satler LF, Pichard AD, Kent KM, Bucher TA, Popma JJ, Leon M. Treatment of in-stent restenosis with excimer laser coronary angioplasty: mechanisms and results compared with PTCA alone. Circulation 1997;96:2183-2189. 
14. Izumi M, Suzuki T, Matsubara T. Results of cutting balloon angioplasty for stent restenosis: Japanese multicenter registry [Abstract]. J Am Coll Cardiol 1998;31:235A.

15. Chevalier B, Royer T, Guyon P, Glatt B. Treatment of in-stent restenosis: short and midterm results of a pilot randomised study between balloon and cutting balloon [Abstract]. J Am Coll Cardiol 1999;33(2;Suppl A):62A.

16. Baim DS, Levine MJ, Leon MB, Levine S, Ellis SG, Schatz RA. Management of restenosis within the Palmaz-Schatz coronary stent (the U.S. multicenter experience). Am J Cardiol 1993;71: 364-366.

17. Macander PJ, Roubin GS, Agawal SK. Balloon angioplasty for the treatment of in-stent restenosis: feasibility, safety and efficacy. Cathet Cardiovasc Diagn 1994;32:125-131.

18. Mehran R, Mintz G, Popma J, Pichard AD, Satler LF, Kent KM, Griffin J, Leon MB. Mechanisms and results of balloon angioplasty for the treatment of in-stent restenosis. Am J Cardiol 1996;78:618-622.

19. Mintz GS, Hoffman R, Mehran R, Pichard AD, Kent KM, Satler LF, Popma JJ, Leon MB. In-stent restenosis: the Washington Hospital Center experience. Am J Cardiol 1998;81(7A):7E-13E.

20. Mehran R, Dangas G, Abizad AS, Mintz GS, Lanksy AJ, Satler LF, Pichard AP, Kent KM, Stone GW, Leon MB. Angiographic patterns of in-stent restenosis: classification and implications for long-term outcome. Circulation 1999;100:1872-1878.

21. Verin V, Popowski Y, Urban P, Belenger J, Redard M, Costa M, Widmer M-C, Michel Rouzaud, Nouet P, Grob E, Schwager M, Kurtz JM, Rutishauser W. Intra-arterial beta irradiation prevents neointimal hyperplasia in a hypercholesterolemic rabbit restenosis model. Circulation 1995;92:2284-2290.

22. King SB III, Williams DO, Chougule P, Klein JL, Waksman R, Hilstead R, Macdonald J, Anderberg K, Crocker IR. Endovascular $\beta$-radiation to reduce restenosis after coronary balloon angioplasty: results of the Beta Energy Restenosis Trial (BERT). Circulation 1998;97:2025-2030.

23. Teirstein PS, Massullo V, Jani S, Popma JJ, Mintz GS, Russo RJ, Schatz RA, Guarneri EM, Steuterman S, Morris NB, Leon MB, Tripuraneni P. Catheter-based radiotherapy to inhibit restenosis after coronary stenting. N Engl J Med 1997;336:1697-1703.

24. Waksman R, White LR, Chan RC, Bass WG, Geirlach LM, Mintz GS, Satler LF, Mehran R, Serruys PW, Lanksy AJ, Fitzgerald P, Bhargava B, Kent KM, Pichard AD, Leon MB. Intracoronary $\gamma$-radiation therapy after angioplasty inhibits recurrence in patients with in-stent restenosis. Circulation 2000;101:2165-2171.

25. Leon MB, Moses JW, Lanksy AJ, Wong SC, Nawaz DM, Whit- low PL, Fish DR, Kluck B, Gorgianni J, Kuntz RE, Teirstein PS. Intracoronary gamma radiation for the prevention of recurrent in-stent restenosis: final results from the Gamma I trial (Abstract). Circulation 1999;100:1-75.

26. Bonan R, Meerkin D, Bertrand O. Geographic miss: What is it? J Invas Cardiol 1999;11:749-756.

27. Popma JJ, Heuser R, Suntharalingam M, Teirstein PS, Massullo V, Bass T, Henderson R, Silber S, von Rottkay P, Lansky AJ, Bonan R, Kuntz RE for the START Investigators. Late clinical and angiographic outcomes after use of beta radiation for the treatment of in-stent restenosis: results from the stents and radiation therapy (START) trial. Forty-ninth Annual Scientific Sessions of the American College of Cardiology, March 2000.-

28. Sabaté M, Kay IP, Gijzel AL, Wardeh AJ, van der Giessen, Coen VLMA, Ligthart JMR, Costa MA, Kozuma K, Serrano P, Levendag P, Serruys P. Compassionate use of intracoronary betairradiation for treatment of recurrent in-stent restenosis. J Invas Cardiol 1999;11:582-588.

29. Albiero R, Adamian M, Kobayashi N, Amato A, Vaghetti M, Di Mario C, Colombo A. Short- and intermediate-term results of ${ }^{32} \mathrm{P}$ radioactive $\beta$-emitting stent implantation in patients with coronary artery disease: the Milan dose-response study. Circulation 2000; 101:18-26

30. Costa MA, Sabaté M, van der Giessen WJ, Kay IP, Cervinka P, Ligthart JMR, Serrano P, Coen VLMA, Levendag PC, Serruys $\mathrm{PW}$. Late coronary occlusion after intracoronary brachytherapy. Circulation 1999;100:789-792.

31. Waksman R. Late thrombosis after radiation: sitting on a time bomb. Circulation 1999;100:780-782.

32. Hehrlein C, Stintz M, Kinscherf R, Schlosser K, Huttel E, Friedrich L, Fehsenfeld P, Kubler W. Pure beta-particle-emitting stents inhibit neointima formation in rabbits. Circulation 1996;93: 641-645.

33. Carter AJ, Laird JR, Bailey LR, Hoopes TG, Farb A, Fischell DR,. Fischell RE, Fischell TA, Virmani R. Effects of endovascular radiation from a $\beta$-particle-emitting stent in a porcine coronary restenosis model: a dose-response study. Circulation 1996;94: $2364-2368$.

34. Elezi S, Kastrati A, Pache J, Wehinger A, Hadamitzky M, Dirschinger J, Neumann F-J, Schömig A. Diabetes mellitus and the clinical and angiographic outcome after coronary stent placement. J Am Coll Cardiol 1998;32(7):1866-1873

35. Williams DO. Radiation vascular therapy: a novel approach to preventing restenosis. Am J Cardiol 1998;81(7A):18E-20E. 